\title{
Motivation and satisfaction among polyclinic volunteers at the 2002 Winter Olympic and Paralympic Games
}

\author{
J C Reeser, R L Berg, D Rhea, S Willick
}

Br J Sports Med 2005;39:e20 (http://www.bjsportmed.com/cgi/content/full/39/4/e20). doi: 10.1136/bjsm.2004.015438

See end of article for authors' affiliations

Correspondence to:

Dr Reeser, Marshfield

Clinic Department of

Physical Medicine, 1000

North Oak Avenue,

Marshfield, WI 54449

USA; reeser.jonathan@

marshfieldclinic.org

Accepted

23 November 2004
Background: The Olympic and Paralympic Games rely heavily on volunteers to provide many essential services, including medical care of athletes.

Objective: This preliminary investigation sought to characterise the motivational influences and factors responsible for the satisfaction of Olympic and Paralympic healthcare volunteers.

Methods: The 2002 Winter Games polyclinic healthcare volunteers were asked to complete a questionnaire designed to elicit information about their motives for volunteering and the factors that contributed to their satisfaction with their volunteer experience.

Results: There was no significant difference in the motivation or satisfaction summary scores based on event worked. There was a strong positive correlation between motivation and satisfaction. Physician respondents had a lower mean motivation score than did non-physician volunteers.

Conclusions: There were no significant motivational differences between Olympic and Paralympic volunteers, but there were several differences noted between physician and non-physician volunteers. The 2002 polyclinic volunteers appear to have been motivated by a complex process best described as "enlightened self interest," and all were generally well satisfied with their experience. These results may assist organisers of future Games in selecting appropriately motivated volunteer personnel and creating rewarding work environments for them.
$\mathrm{S}$ ince being established by Pierre de Coubertin in 1896, the modern Olympic Games have grown into the largest sporting event in the world. The Paralympic Games, an outgrowth of the International Wheelchair Games inaugurated by Sir Ludwig Guttman in 1948, have similarly grown since their inception and are the second largest international participatory sporting event world wide. To an extent perhaps unmatched by other sporting events, the Olympic and Paralympic Games depend on volunteers to provide a variety of essential services, ranging from transportation and language translation to medical care. Over the last several Olympiads, the Olympics have become increasingly reliant on a capable cadre of volunteers (table 1). Not surprisingly, Dr Jacques Rogge, President of the International Olympic Committee, has concluded, "...without [volunteers], sport and Olympism would be orphans. It would not be possible to organize the Olympic Games and competitions at all levels without volunteers' commitment and dedication". ${ }^{\prime}$

About 20000 people volunteered during the 2002 Olympic and Paralympic Winter Games in Salt Lake City, Utah. It has been estimated that the Salt Lake Organizing Committee received more than three applications for each volunteer position. The volunteer selection and training process was rigorous, and the results were by all accounts outstanding. According to one observer, "Salt Lake took volunteerism to an art form; they set the new standard". ${ }^{3}$ Furthermore, the heavy reliance on volunteers has been credited as an important ingredient of the financial success of the Games.

The Salt Lake City Olympic and Paralympic polyclinic served as the central access point for medical care during the Games, providing medical, dental, optical, laboratory, radiological, pharmaceutical, and physical therapy services to the athletes and members of official national delegations. Located within the athlete's village, the polyclinic was operational from 29 January 2002 through 19 March 2002, recording about 2600 visits from athletes, officials, and other accredited personnel during the 48 days it was open. ${ }^{4}$ During this period, about 270 volunteer physicians, nurses, physical therapists, and other medical professionals staffed the polyclinic "around the clock." Although many of these continued to receive wages from their respective employers during their volunteer assignment, they did not receive compensation from the Salt Lake Organizing Committee for the services they rendered at the polyclinic. As their work at the polyclinic was in fact voluntary, each can be considered a "volunteer" as defined by the New York Declaration. ${ }^{5}$

Interestingly, although volunteerism has been declared to serve as a foundation of the Olympic movement and despite the growing reliance on volunteers, no studies investigating the factors that motivate Olympic and Paralympic healthcare personnel to volunteer have been published. There are also no published reports analysing the factors contributing to the satisfaction of Olympic or Paralympic healthcare volunteers. The goal of this exploratory study therefore was to begin to understand the factors that motivated and contributed to the satisfaction of polyclinic volunteers during the 2002 Salt Lake City Olympic and Paralympic Games.

\section{METHODS}

The study protocol was reviewed and approved by the institutional review board. Permission to conduct the study was obtained from the medical commissions of both the International Olympic Committee and the International Paralympic Committee. Volunteer healthcare workers staffing the polyclinic during the Olympic and Paralympic Games were asked to complete a 70 item questionnaire which included 22 items inquiring about factors that may have influenced their decision to volunteer for the Games, and 24 items that explored the factors that may have contributed to their satisfaction with their volunteer experience.

To investigate specific motives for volunteering, we modified Farrell's 28 item special event volunteer motivation scale (SEVMS). ${ }^{6}$ We shortened the SEVMS by removing six items thought to be irrelevant to the polyclinic experience. 
Table 1 Estimated number of volunteers for the Summer and Winter Olympic and Paralympic Games since 1980

\begin{tabular}{|c|c|c|c|}
\hline Summer Games & Number & Winter Games & Number \\
\hline $\begin{array}{l}1984 \text { Los Angeles } \\
1988 \text { Seoul } \\
1992 \text { Barcelona } \\
1996 \text { Atlanta } \\
2000 \text { Sydney } \\
2004 \text { Athens (est) }\end{array}$ & $\begin{array}{l}28742 \\
27221 \\
34548 \\
60422 \\
62000 \\
60000\end{array}$ & $\begin{array}{l}1980 \text { Lake Placid } \\
1984 \text { Sarajevo } \\
1988 \text { Calgary } \\
1992 \text { Albertville } \\
1994 \text { Lillehammer } \\
1998 \text { Nagano } \\
2002 \text { Salt Lake City }\end{array}$ & $\begin{array}{l}6703 \\
10450 \\
9498 \\
8000 \\
9054 \\
32579 \\
20000\end{array}$ \\
\hline
\end{tabular}

The resulting instrument still contained questions that reflected the four motivational factors identified in Farrell's study (see Discussion). Also contained within the questionnaire was a 24 item section in which respondents were asked to offer feedback about factors that we believed were relevant to their satisfaction with their volunteer experience. Responses to all questions were graded using a five point Likert scale, ranging from 1 (strongly disagree) to 5 (strongly agree). Participation was completely voluntary. Participants could pick up the questionnaire at selected distribution points, complete it, and return it to one of several collection points at their convenience. Subjects were encouraged to complete the questionnaire at the conclusion of their volunteer assignment, which typically spanned five to seven days. The data were collected, and standard descriptive statistics were calculated to characterise the respondents' characteristics, as well as their responses to the motivation and satisfaction questions. $\chi^{2}$ analyses were performed to compare physician and non-physician volunteer responses to discrete measures, and the Wilcoxon rank sum test was used with continuous measures. Principle component factor analysis $^{7}$ and analysis of internal consistency using Cronbach's $\alpha$ statistic $^{8}$ were used to determine the validity of creating summary scores for the 22 motivation items and the 24 satisfaction items. The Pearson correlation coefficient was used to evaluate the association between basic characteristics of the volunteers and the motivation and satisfaction summary scores. Statistical comparisons were deemed significant at the $5 \%$ level $(\mathrm{p}<0.05)$.

\section{RESULTS}

A total of 136 of the polyclinic's 270 volunteers (50\%) returned questionnaires. The mean age of the respondents was 40 years (range $24-73$ ), and $52 \%$ of the respondents were male. Forty three percent of the respondents were "physicians"- that is, medical doctors or other terminally degreed medical professionals including dentists, optometrists, and podiatrists $-24 \%$ were certified athletic trainers or physical therapists, $13 \%$ were nurses, and $10 \%$ were medical technologists or assistants. The 59 physician respondents represented $73 \%$ of the total polyclinic physician volunteer

Table 2 Study composition and percentage participation by profession

\begin{tabular}{llll}
\hline Profession & $\begin{array}{l}\text { No of } \\
\text { participants }\end{array}$ & $\begin{array}{l}\text { Total No } \\
\text { of volunteers }\end{array}$ & $\begin{array}{l}\text { Percentage } \\
\text { participation }\end{array}$ \\
\hline Physician & 59 & 81 & 73 \\
Physical therapist/ATC & 33 & 53 & 62 \\
Nurse & 17 & 37 & 46 \\
$\begin{array}{l}\text { Medical assistant or } \\
\text { technologist }\end{array}$ & 13 & 88 & 15 \\
Other medical (eg EMT) & 1 & 11 & 9 \\
\hline
\end{tabular}

13 respondents did not provide information about their profession. ATC, Certified athletic trainer; EMT, emergency medical technician. force (table 2). Only 15 (11\%) of the respondents reported prior Olympic or Paralympic volunteer experience. A nearly equivalent number of physicians and non-physicians responded, and the number of respondents who worked only during the Olympic Games was virtually identical with the number of respondents who volunteered during both the Olympics and Paralympics or during the Paralympics alone (table 3).

Nineteen of the 22 motivation items correlated strongly (Cronbach's $\alpha=0.88$ ) and three items correlated very weakly or negatively with others. Factor analysis verified that the remaining items reflected a single strong factor, and a motivation summary score was created as the mean over these 19 items (table 4). Similar analysis suggested good internal consistency (Cronbach's $\alpha=0.85$ ) and a strong primary dimension for the satisfaction questions, and a summary score was created as the mean over all 24 items (table 5).

The data reveal that service oriented motives generally ranked highest among all subgroups of polyclinic volunteers, although respondents also endorsed motives that indicated a simultaneous desire for self fulfilment. Whereas physician respondents had a lower mean motivation score across all 19 items than did non-physician volunteers (3.8 $v 4.0, \mathrm{p}=$ 0.009 ), there was no significant difference in the mean motivation score based on event worked $(p=0.92)$. There was a negative correlation between age and the motivation summary score that approached statistical significance $(r=$ $-0.20, \mathrm{p}=0.05$ ).

Satisfaction scores were in general quite high, with $91 \%$ of respondents indicating that the experience met or exceeded their expectations, and 97\% reporting that they would be willing to volunteer again in a similar capacity. The highest ranked factors contributing to volunteer satisfaction tended to focus on interpersonal relationships, both between the healthcare providers and with the athletes for whom they cared. As with the motivation score, there was no significant difference in the mean satisfaction score based on event worked $(p=0.30)$. Unlike motivation, however, age showed no association with the satisfaction summary score $(r=$ 0.02, $\mathrm{p}=0.82$ ). Female volunteers expressed higher satisfaction with their volunteer experience than did male volunteers $(4.2 \vee 4.0, \mathrm{p}=0.026)$. Physicians tended to be

Table 3 Event worked analysed according to profession

\begin{tabular}{lll}
\hline & \multicolumn{2}{l}{ Respondents } \\
\cline { 2 - 3 } Event worked & Physicians (\%) & Non-physicians (\%) \\
\hline Olympics only & $29(49.2)$ & $31(48.4)$ \\
Paralympics only & $7(11.9)$ & $3(4.7)$ \\
Both events & $23(39.0)$ & $30(46.9)$ \\
Total & 59 & 64 \\
\hline
\end{tabular}

The analysis excludes the 13 participants who did not report their profession. 
Table 4 Motivation scores for physicians $v$ non-physicians and by event worked

\begin{tabular}{|c|c|c|c|c|c|}
\hline \multirow[b]{2}{*}{ Motivation factor } & \multicolumn{3}{|c|}{ Results by event worked } & \multicolumn{2}{|c|}{ Results by profession } \\
\hline & Olympics & Paralympics & Both & Physician & Non-physician \\
\hline It was the chance of a lifetime & 4.60 & 3.91 & 4.53 & 4.39 & 4.58 \\
\hline I wanted to do something worthwhile & 4.46 & 4.27 & 4.38 & 4.46 & 4.42 \\
\hline I wanted to help make the event a success & 4.34 & 4.36 & 4.48 & 4.39 & 4.36 \\
\hline I wanted to work with different people & 4.31 & 4.09 & 4.55 & 4.29 & 4.52 \\
\hline Volunteering makes me feel part of the Olympic/Paralympic community & 4.15 & 4.00 & 4.25 & 4.00 & 4.29 \\
\hline Volunteering creates a better society & 4.09 & 3.82 & 4.27 & 3.97 & 4.25 \\
\hline I wanted an opportunity to work with elite athletes & 4.09 & 3.73 & 3.92 & 3.90 & 4.19 \\
\hline I enjoy winter sports & 4.05 & 4.00 & 4.05 & 4.02 & 4.14 \\
\hline I felt my skills were needed & 4.02 & 4.00 & 4.07 & 4.12 & 3.98 \\
\hline I wanted to broaden my horizons & 4.00 & 3.73 & 4.14 & 3.80 & 4.24 \\
\hline Being a volunteer at this event is prestigious & 3.86 & 3.64 & 3.81 & 3.69 & 3.94 \\
\hline I wanted an educational experience & 3.72 & 3.55 & 3.75 & 3.54 & 3.89 \\
\hline Being a volunteer makes me feel better about myself & 3.68 & 3.64 & 3.81 & 3.54 & 3.83 \\
\hline Volunteering in this capacity is challenging & 3.56 & 3.36 & 3.58 & 3.50 & 3.57 \\
\hline I wanted to develop my skills & 3.52 & 3.55 & 3.30 & 3.22 & 3.61 \\
\hline I wanted to help out in any capacity & 3.52 & 3.18 & 3.93 & 3.32 & 3.87 \\
\hline I wanted to vary my regular activities & 3.25 & 3.82 & 3.76 & 3.29 & 3.67 \\
\hline I wanted an opportunity to network professionally & 3.12 & 3.18 & 2.98 & 2.83 & 3.38 \\
\hline I have past experience providing similar service & 3.08 & 3.18 & 3.24 & 3.27 & 3.03 \\
\hline Mean motivation score & 3.9 & 3.7 & 4.0 & 3.8 & 4.0 \\
\hline
\end{tabular}

Subgroup mean motivational scores did not differ significantly by event, but physicians did have a significantly lower mean motivational score than non-physicians. See text for discussion.

Both, Olympics + Paralympics.

somewhat less satisfied by their experience than nonphysicians, although the observed difference did not reach significance $(p=0.08)$. Significantly fewer physician than non-physician volunteers planned to use their volunteer experience to help market their professional practices $(\mathrm{p}=$ 0.039 ), even though an equivalent percentage of physicians to non-physicians felt that the experience would benefit their careers. There was a strong positive correlation between motivation and satisfaction $(r=0.42, \mathrm{p}<0.001)$.

\section{DISCUSSION}

To our knowledge, this is the first study to investigate factors responsible for the motivation and satisfaction of Olympic and Paralympic polyclinic volunteers. We acknowledge some methodological shortcomings, but we believe that the study succeeds in providing preliminary insight into this topic. Although we would have preferred more robust participation, we feel the $50 \%$ overall response rate is acceptable, given that participation was strictly voluntary and that those who wished to participate had to first find and then complete the questionnaire. Despite these limitations, our response rate is comparable to that obtained by Williams et al ${ }^{11}$ in their 1994 investigation of volunteer motivation at an elite winter sporting event. All categories of polyclinic healthcare volunteers were represented among the study participants, but for reasons that are not immediately obvious to us the

Table 5 Satisfaction scores for physicians $v$ non-physicians and by event worked

\begin{tabular}{|c|c|c|c|c|c|}
\hline \multirow[b]{2}{*}{ Satisfaction factor } & \multicolumn{3}{|c|}{ Results by event worked } & \multicolumn{2}{|c|}{ Results by profession } \\
\hline & Olympics & Paralympics & Both & Physician & Non-physician \\
\hline Working relationships were collegial & 4.62 & 4.82 & 4.54 & 4.64 & 4.55 \\
\hline The athletes were appreciative of the care I provided & 4.53 & 4.45 & 4.73 & 4.59 & 4.62 \\
\hline My background was appropriate for the level of expertise demanded & 4.52 & 4.18 & 4.47 & 4.47 & 4.43 \\
\hline The athletes were agreeable to work with & 4.51 & 4.64 & 4.61 & 4.47 & 4.64 \\
\hline The athletes' attitudes contributed to a positive experience & 4.45 & 4.50 & 4.50 & 4.45 & 4.50 \\
\hline My professional colleagues exhibited positive attitudes & 4.43 & 4.50 & 4.48 & 4.42 & 4.48 \\
\hline I enjoyed the opportunity to interact with people from other cultures & 4.38 & 4.50 & 4.45 & 4.37 & 4.45 \\
\hline Staffing levels were acceptable & 4.38 & 4.50 & 4.38 & 4.37 & 4.40 \\
\hline I feel I made a positive contribution to the athletes' experience & 4.35 & 4.45 & 4.48 & 4.42 & 4.41 \\
\hline The experience was challenging and stimulating & 4.35 & 4.45 & 4.43 & 4.25 & 4.48 \\
\hline The facility was well designed & 4.29 & 4.50 & 4.35 & 4.27 & 4.43 \\
\hline Support services made a positive contribution to the polyclinic & 4.29 & 4.50 & 4.30 & 4.35 & 4.31 \\
\hline Support services were adequate & 4.28 & 4.55 & 4.20 & 4.34 & 4.23 \\
\hline "Back up" was timely and adequate & 4.06 & 4.36 & 4.10 & 4.09 & 4.16 \\
\hline The physical plant was acceptable & 4.06 & 4.18 & 4.13 & 4.17 & 4.06 \\
\hline The work load was acceptable & 3.92 & 3.91 & 4.07 & 3.88 & 4.06 \\
\hline Translation services were adequate & 3.89 & 4.00 & 3.76 & 3.98 & 3.85 \\
\hline The case mix was varied and interesting & 3.83 & 3.73 & 4.08 & 3.64 & 4.14 \\
\hline The method for allocating shifts was fair and unbiased & 3.55 & 3.41 & 3.58 & 3.35 & 3.75 \\
\hline The pace of patient-seeing activity was acceptable & 3.47 & 3.55 & 3.66 & 3.38 & 3.68 \\
\hline I found the pre-Games training to be acceptable & 3.45 & 3.00 & 3.50 & 3.05 & 3.66 \\
\hline The level of pre-Games communication was acceptable & 3.40 & 3.00 & 3.70 & 3.34 & 3.68 \\
\hline Cost of living during the Games was not prohibitive & 3.25 & 3.33 & 3.29 & 3.11 & 3.41 \\
\hline I had no real problems securing housing arrangements & 3.23 & 3.60 & 3.39 & 3.22 & 3.43 \\
\hline Mean satisfaction score & 4.1 & 4.1 & 4.1 & 4.0 & 4.2 \\
\hline
\end{tabular}

Subgroup mean satisfaction scores did not differ significantly by event, or between physicians and non-physicians. See text for discussion. Both, Olympics + Paralympics. 
response rate among physicians was considerably higher than for the other volunteer healthcare professionals who chose to participate in the study.

As with all voluntary questionnaire based research, there is a real possibility that our results suffer from an inherent self selection bias. With that caveat, it is apparent that the polyclinic volunteers who participated in the study were generally service oriented-that is, they valued the opportunity to contribute to the success of the Games and make a difference in the lives of the athletes participating in this unique event. Kofi Annan, Secretary General of the United Nations, has stated that "The traditional view of volunteering as purely altruistic is evolving into one characterised by benefits to everyone involved, in other words, reciprocity. The notion of 'enlightened self interest' captures well the reciprocity that is at the root of volunteering".' The results of our study would appear to support this view. The leading overall motive, that of contributing to the success of a "once in a lifetime" event, itself suggests a component of altruism (donation of services) and of self interest (being a part of a unique event). Although the highest ranking motives of polyclinic volunteers were largely altruistic, the leading motives also reflect the reciprocity about which Mr Annan spoke-for example, the opportunity to work with different people and elite athletes, and to feel a part of the Olympic/ Paralympic community.

Entering into the study, we suspected that there might be significant motivational differences between polyclinic volunteers based on the event worked. However, this hypothesis was not supported by the data. Although there were slight differences in the rank order of the mean responses to items in the modified SEVMS among the three subgroupings identified (Olympics only, Paralympics only, and both events), there was no significant difference between the mean motivational scores based on the event worked. Additional analysis revealed that there were no significant sex specific motivational factors. Although the relative importance of specific motivational factors appeared to be similar for the physician and non-physician cohorts, physicians had slightly different (generally lower) motivation scores than the non-physician volunteers (as reflected by the significantly lower mean motivation score among physicians than among the non-physician group). The practical importance of this observation is unclear, but we suspect it reflects an intrinsic conservatism on the part of the physician cohort. In this regard, it is perhaps worth noting that physicians were less interested in using their polyclinic experience for self promotion than were non-physicians.

Satisfaction was assessed using a series of 24 questions which, like the modified SEVMS, formed a unidimensional scale. The lowest satisfaction scores were awarded to preGames communication and training, although these aspects of the volunteer experience may not have been unique to polyclinic volunteers/management. Housing and cost of living also scored poorly on the satisfaction scale, reflecting the high demand for, and cost of, housing during the Salt Lake City Games. The factors scoring most highly on the satisfaction scale indicated that the volunteers valued the interpersonal relationships into which they entered, and that they found satisfaction in the appreciation demonstrated by

\section{What is already known on this topic}

The Olympic and Paralympic Games rely heavily on volunteers to provide many essential services, including medical care of athletes. It is not known what motivates these volunteers. the athletes for the care they received. Whereas there was no difference between the mean satisfaction scores based on event worked, female volunteers expressed greater satisfaction overall than did male volunteers. In addition, physicians tended to have lower overall satisfaction scores, particularly with regard to the administrative aspects of the volunteer experience, such as pre-Games training and the allocation of shifts during the operational period. It is possible that these lower scores reflect specific concerns among the physician volunteers, or it may be that the lower scores reflect a higher set of expectations shared by the cohort of physician respondents. We observed a strong positive correlation between motivation and satisfaction scores. Whether the specific motivation items that correlated highest with satisfaction have positive predictive value must await further study.

Although there is a considerable body of literature discussing the motivation for volunteering in general, the scientific literature investigating the motivation of sporting event volunteers in particular is sparse. Various theoretical constructs have been developed to explain what motivates individuals to contribute their time and energy to athletic events. Strigas $e t$ al $^{10}$ investigated motivational factors among volunteers for the Florida Gulf Beaches Marathon and identified five motivational factors (material, leisure, egoistic, purposive, and external). Williams et al ${ }^{11}$ examined volunteer motivation during the 1994 Men's Skiing World Cup competition in Whistler, $\mathrm{BC}$, Canada and reported that the most important reason for volunteering was socialisation with people who shared common interests. Farrell et $a l^{6}$ found that, among volunteers at the 1996 Canadian Women's Curling Championship, four empirical factors contributed to volunteer motivation (purposive, solidary, external traditions, and commitments), prompting the authors to conclude that volunteering at this event was a multidimensional phenomenon with predominantly purposive incentives.

In their study, Farrell et $a l^{6}$ used a 28 item questionnaire which they developed on the basis of research previously performed by Cnaan and Goldberg-Glen, ${ }^{12}$ which they termed the SEVMS. Interestingly, however, Cnaan and GoldbergGlen originally reported that the vast majority of the 28 motives commonly reported in the human resources volunteerism literature (on which the SEVMS is based) could be adequately represented by a single unidimensional factor, and therefore concluded that "volunteers are both altruistic and egoistic. That is, volunteers do not distinguish between types of motives; rather they act on both". ${ }^{12}$ This conclusion is quite similar to the concept of reciprocity and enlightened self interest mentioned by Mr Annan.

The 22 item modified SEVMS that we used to measure motivation in this study produced a unidimensional grouping of volunteer motives. From a practical standpoint, this determination permitted us to simplify the correlation analyses subsequently performed to investigate the relation between motivation and other factors. Although our original goal in investigating the motivation of polyclinic workers was

\section{What this study adds}

The volunteers in this study of the 2002 Winter Olympic and Paralympic Games appear to have been motivated by a complex process best described as "enlightened self interest," and all were generally well satisfied with their experience. These results may assist organisers of future Games in selecting appropriately motivated volunteer personnel and creating rewarding work environments for them. 
not to enter into the debate surrounding the theoretical underpinnings of volunteerism, the fact that our analysis suggests that the motives of the polyclinic volunteers were unidimensional would appear to support the analysis of Cnaan and Goldberg-Glen. ${ }^{12}$ That being said, we question the extent to which these analyses and models can be directly compared, given the considerable differences inherent in large sporting events. Furthermore, we suspect that it will prove difficult to arrive at a simple theoretical model that consistently predicts or explains the motives of groups of people with varying professional, socioeconomic, and cultural backgrounds volunteering at different sporting events that differ in status and scope.

\section{CONCLUSIONS AND RECOMMENDATIONS}

Polyclinic volunteers during the 2002 Salt Lake City Games appear to have been motivated by a complex process that may be described as "enlightened self interest." Furthermore, the polyclinic volunteers reported being generally well satisfied with their volunteer experience. As discussed, one of the leading factors contributing to volunteer satisfaction was the athlete's appreciation of the services rendered. This implies that positive feedback and public recognition of the volunteers' dedicated efforts should be a routine strategy for volunteer personnel management, a recommendation that has been eloquently espoused by Brettell. ${ }^{13}$ Furthermore, it may be that the characteristics of the Salt Lake City polyclinic healthcare volunteer corps-that is, young, relatively inexperienced-may have contributed to its success, as these are factors cited by Brettell as potentially contributing to the memorable warmth and hospitality of the volunteers at the 2000 Sydney Olympic and Paralympic Games.

Volunteers have become an indispensable component of the workforce during large sporting events such as the Olympic and Paralympic Games. Selecting volunteers who are at once competent and have appropriate motives would appear to be important to the success of the undertaking. Further study may be warranted to confirm and better understand the implications of our preliminary observations with regard to the motivation of healthcare volunteers, and to determine whether our findings may also apply to Olympic/ Paralympic volunteers in general or if (as we suspect) they are specific to this unique segment of the volunteer force. The motivation scale used for this study, if validated through further investigation, may prove to be a useful screening tool in the selection of future polyclinic volunteers. Finally, we advocate ongoing investigation and analysis of factors responsible for volunteer satisfaction, so that the athletes of the Games of Turin, Beijing, Vancouver, and beyond might benefit.

\section{Authors' affiliations}

J C Reeser, Marshfield Clinic Department of Physical Medicine, Marshfield, WI, USA

R L Berg, Marshfield Clinic Research Foundation, Marshfield

D Rhea, Texas Christian University, Fort Worth, TX, USA

S Willick, University of Utah, Salt Lake City, UT, USA

Competing interests: no author or related institution has received any financial benefit from research in this study.

\section{REFERENCES}

1 Rogge J. Volunteerism. Olympic Review 2001;42:3.

2 Karlis G. Volunteerism and multiculturalism: a linkage for future Olympics. Sport Journal, 2003;6. Available online at http://www.thesportjournal.org/ 2003Journal/Vol6-No3/Volunteerism.asp.

3 Waldman P. How the Games turned a profit: lots of volunteers. Wall Street Journal 27 February 2002;(Sect B): 1.

4 Reeser JC, Willick S, Elstad M. Medical services provided at the Olympic Village polyclinic during the 2002 Salt Lake City Winter Games. WMJ 2003;102:20-5.

5 The New York Declaration. Olympic Review 2001;42:10.

6 Farrell JM, Johnston ME, Twynam GD. Volunteer motivation, satisfaction and management at an elite sporting competition. Journal of Sport Management $1998 ; 12: 288-300$.

7 Morrison DF. Multivariate statistical methods. New York: McGraw-Hill, 1976.

8 Cronbach $\mathrm{L}$. Coefficient alpha and the internal structure of tests. Psychometrika 1951;16:297-334.

9 Annan K. Volunteering: an evolving paradigm. Olympic Review $2001 ; 42: 27-30$.

10 Strigas A, Jackson EN, Ratliffe T. Investigation of the demographic profile and the development of a model of motivational factors for volunteers in recreational sport events. Presented at the American Alliance for Health, Physical Education, Recreation, and Dance National Convention and Exposition. Available online at http://aahperd.confex.com/aahperd/2002/ finalprogram/paper_2353.htm (accessed 14 Jan 2004).

11 Williams PW, Dossa KB, Tompkins L. Volunteerism and special event management: a case study of Whistler's Men's World Cup of Skiing. Festival Management \& Event Tourism 1995;3:83-95.

12 Cnaan RA, Goldberg-Glen RS. Measuring motivation to volunteer in human services. J Appl Behav Sci 1991;27:269-84.

13 Brettell D. The Sydney volunteers. Olympic Review 2001;42:37-43. 